\title{
High Temperature Spalling of Alumina Bars
}

\author{
J. Najar and M. Müller-Bechtel
}

Lehrstuhl A für Mechanik, Technische Universität München Boltzmannstr. 15, 85747 Garching, Germany

\begin{abstract}
Spalling experiments with alumina bars performed at teinperatures up to $1500^{\circ} \mathrm{C}$ have been conducted in a new apparatus. A cylindrical uninstrumented specimen is located in an open-end furnace and dynamically loaded in tension by the reflection of a compressive pulse from its free end. A bridging piece of the same impedance covers the transition zone between the measuring rod and the specimet, which is positioned in the homogeneous part of the thermal field within the furnace. The data acquisition conswis of the measuring of the incoming and reflected pulses in the transmitter, the temperature distribution in the furnace, and the positions of the spalling sites in the specimen. The evaluation procedure takes into account the high-temperature corrections, due to temperanre-induced drop in the wave velocity and impedance of the bridging piece, This results in the change of the dispersion and the shape of the pulse. The results of the experiments show that the strength drop with the temperature growing up to $1500^{\circ} \mathrm{C}$.
\end{abstract}

Résumé : Des expériences de rupture dynamique de barres d'alumine elfectuées à des températures jusquà $1500^{\circ} \mathrm{C}$ ont été conduites à l'aide d'un nouvel appareil. L'éprouvette cylindrique est placée dans un fourneau et est chargée dynamiquement sous tension par la rétlexion d'une impulsion de compression. L'acquisition des caractéristiques consiste dune part en le calcul des impulsions transmises et réfléchies dans le transmetteur et la distribution de la température dans le fourneau, d'autre part en la mesure des positions des sites de rupture dynamique dans l'éprouvette. La procédure d’évaluation comprend les corrections pour de tres hautes températures. à cause du changement thermique qui affecte la vitesse des ondes et l'impédance des connexions. Par conséquent, la dispersion el la forme de l'impulsion sont modifiées. Les résultats expérimentaux montrent que la résistance diminue simultanément avec l'augmentation dẻ la température jusquà $1500^{\circ} \mathrm{C}$.

\section{INTRODUCTION}

A brief account is given on the results of an extensive series of spalling tests with alumina ceramic bars at temperature up to $1500^{\circ} \mathrm{C}$, conducted with a new experimental set-up. The apparatus has been developed specifically for dynamic testing of high performance ceramics. Numerous tests of the same kind of ceramic bars had been conducted earlier at room temperature [1]. The results showed a substantial dependence of the spalling strength on the specimen's diameter. They indicated also at a different mechanism of energy consumption at dynamic failure, as compared with that of a single crack resistance energy measurements at static loads [2]. The results presented here show a clear dependence of the spall strength on the temperature in the whole investigated range, complementing and improving thus the earlier observations [3], due to an improved evaluation procedure.

\section{EXPERIMENTAL ARRANGEMENT}

For the purpose of dynamic tensile testing of ceramics, the typical SHPB pulse initiation and gauging arrangements have been combined with the spalling principle, as applied to uninstrumented slender cylindrical specimens, Figure 1. The evaluation procedure consists in the computation of the transient stress pulse in the specimen, Figure 2. It is based on the measurements of the initiated and reflected pulses in the transmitter bar, taking into account the geometrical dispersion of the wave-trains as they travel along substantial distances. Impedance relations at the interfaces of the bars are involved. 


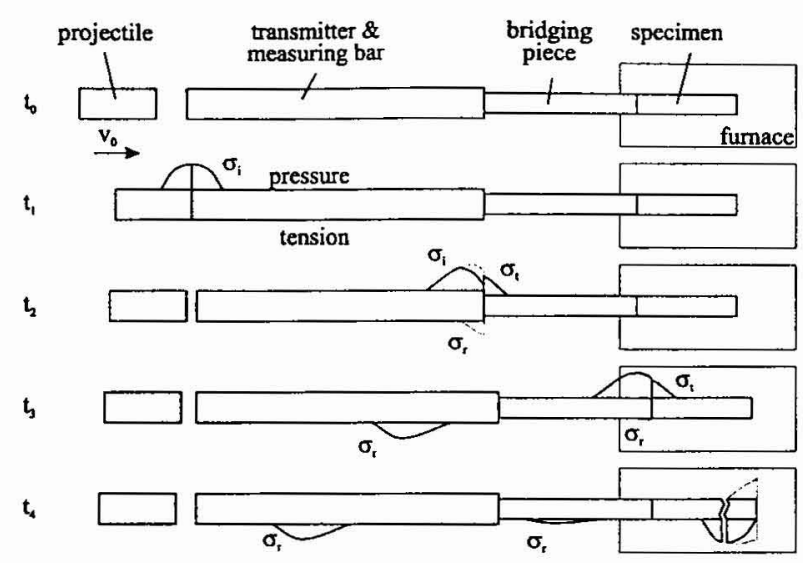

Figure 1: Experimental arrangement

A special procedure has been developed to distinguish between the primary and the secondary spalling sites [4]. The knowledge of the primary spall location enables the determination of the stress at the spall. Due to the negligible fracture delay time in the tested alumina ceramics, the latter quantity can be further defined as the spalling strength of the specimen.

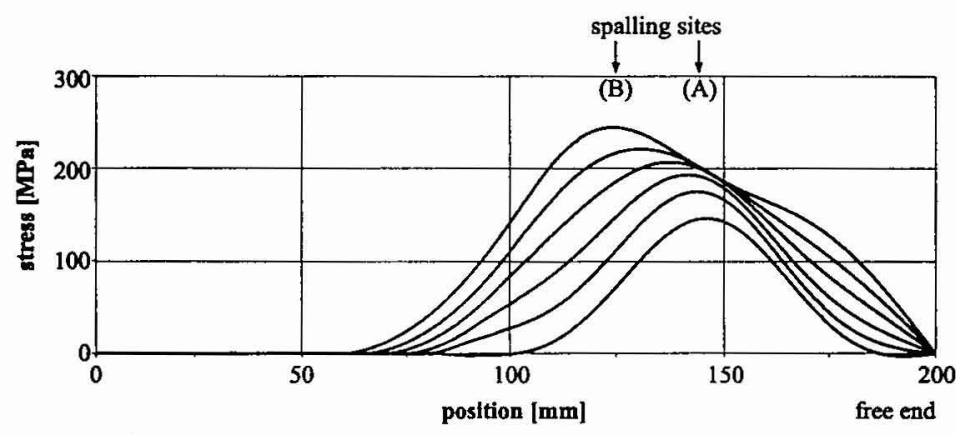

Figure 2: Resulting transient pulses in the specimen, in a time-step sequence $0.5 \mu \mathrm{s}$

All these procedures have been successfully tested at the room temperature [4]. The results on the dependence of the strength on the size of the specimen have been obtained in long series of experiments, exhibiting at the same time the advantages of the testing arrangement: low experimental scatter, low costs of conducting serial tests, easy handling of brittle specimens of ceramics.

The main advantage of the arrangement, however, is related to its adaptability to dynamic testing of ceramics at elevated temperatures. Applied to specimens located within an open-end furnace, Figure 3, the arrangement includes a bridging piece of the same material and diameter as the specimen itself. It is placed into the thermal transition zone, and serves the bridging of the inhomogeneous temperature field at the entrance of the furnace. The specimen itself is positioned in the area of homogeneous temperature distribution. The typical distribution in the unit, Figure 3, has as a consequence a variable wave velocity field in the transition region, due to thermal expansion and thermal dependence of elasticity moduli of the ceramics.

In order to determine the dependence of the wave velocity on the temperature, auxiliary tests have been conducted with long rods of the tested material. They were subsequently positioned in two different predetermined locations within the furnace, Figure 4. Gauging the pulse propagation times at reflections from the hot free end of the rods enabled a relatively easy determination of the effective wave velocity at single chosen temperature levels, Figure 5. 


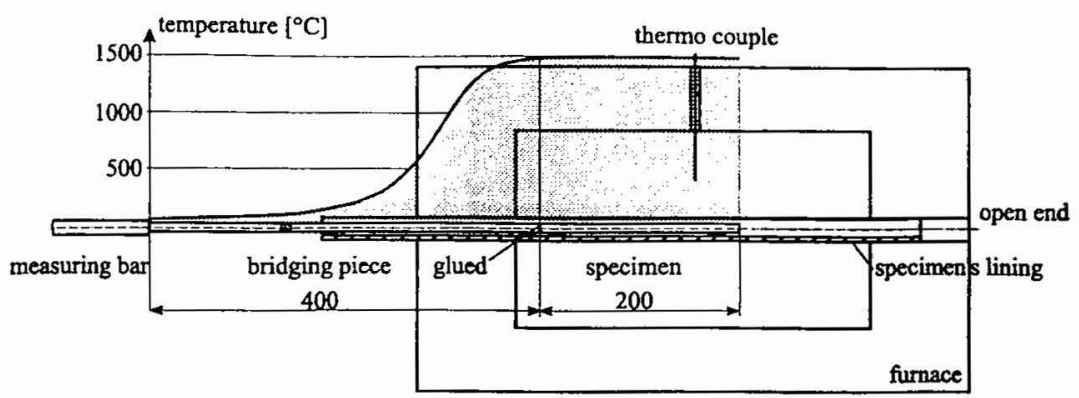

Figure 3: Experimental set-up and the temperature distribution in the unit bridging piece - specimen

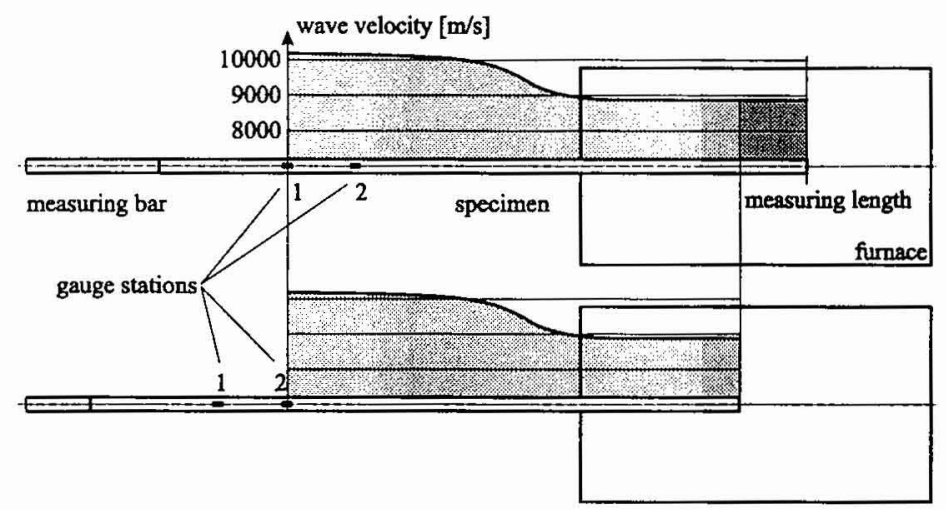

Figure 4: Measurement of the wave velocity at elevated temperatures

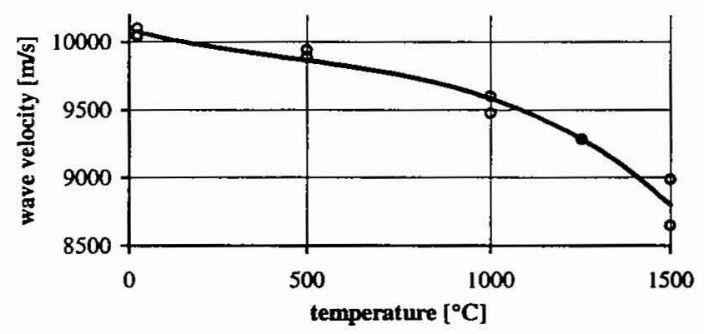

Figure 5: Temperature dependence of the wave velocity

\section{EVALUATION PROCEDURE}

Complementary to the evaluation procedure for spalling strength at the room temperature [4], three additional effects related to the elevated temperatures' influence on the stress pulse propagation in the specimen need to be taken into account.

1) The drop in the wave speed $c_{0}$ with the temperature leads to a shortening of the pulse length thus changing the resulting stress distribution after the free-end-reflection, Figure 6.

2) The change of the wave speed and the shift towards the short-wave spectrum in the Fourier decomposition of the stress pulse leads to an amplification of the geometrical dispersion effects in the bridging piece and the specimen: At a given radius $\mathrm{R}$ of the cylindrical bar, any Fourier component of the pulse with a wave length $\lambda$ will get shifted along the dispersion curve towards lower phase velocities $c_{\lambda}$ and higher $R / \lambda$ ratios, Figure 7 .

3) Density $\rho$, cross-section area $A$ and wave speed $c$ change at increasing temperature what results in decreasing bar impedances of the bridging piece, Figure 8. 


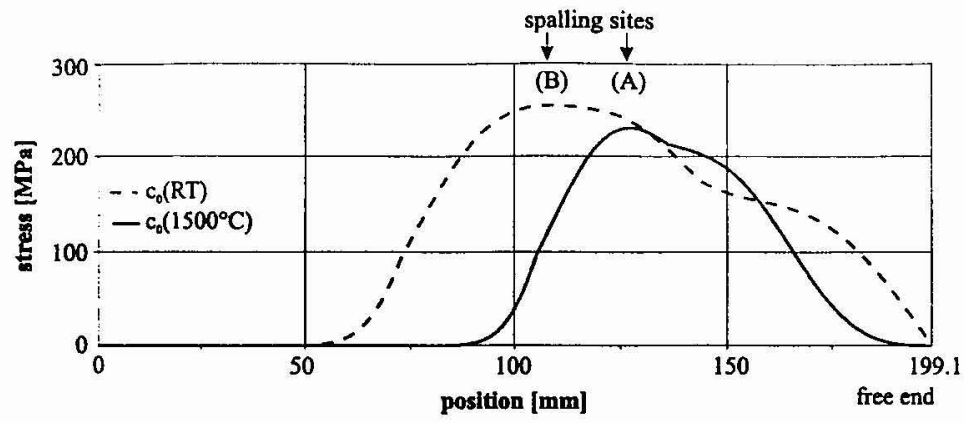

Figure 6: Influence of the decreasing wave velocity on the stress distribution in the specimen

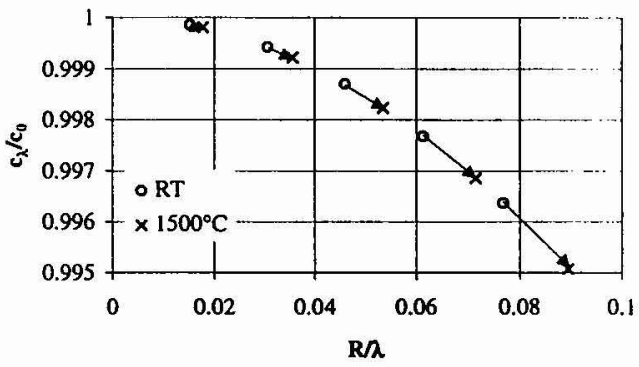

Figure 7: Influence of the wave velocity on the geometrical dispersion of the pulse

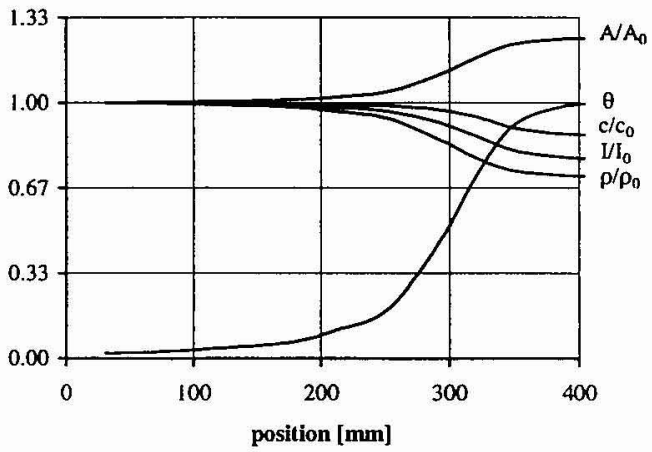

Figure 8: Temperature distribution in the bridging piece and its influence on cross section area, wave velocity, density and bar impedance

The consequence of it is an incremental pulse-matching procedure at each step of the simulation of the stress pulse propagation: the incident stress $\sigma_{i}$ and the reflected pulse $\sigma_{i}{ }^{r}$ within the $i$-th distance increment have to be matched by means of the force balance and mass velocity compatibility conditions with the pulse $\sigma_{i+1}$ transmitted into the (i+1)-st distance increment, Figure 9. The method of characteristics is applied then in the evaluation of the rather complicated wave pattern, Figure 10 , featuring curvilinear wave fronts in the diagram position $x$ versus time $t$. For the measured temperature distribution in the bridging piece one gets at $1500^{\circ} \mathrm{C}$ temperature in the furnace a transmission into the specimen of some $89 \%$ of the initial pulse amplitude. The amplitude of the primary reflection makes $7 \%$ of the initial pulse amplitude although due to the pulse length extension it carries some $11 \%$ of the initial pulse energy with. The secondary reflections are practically negligible, carrying some $0.3 \%$ of the stress amplitude, i.e. remaining within the experimental error. 


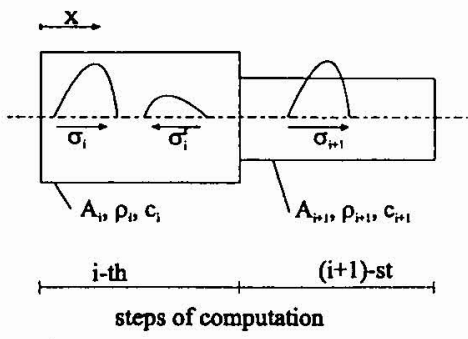

Figure 9: Partial reflection at an element boundary

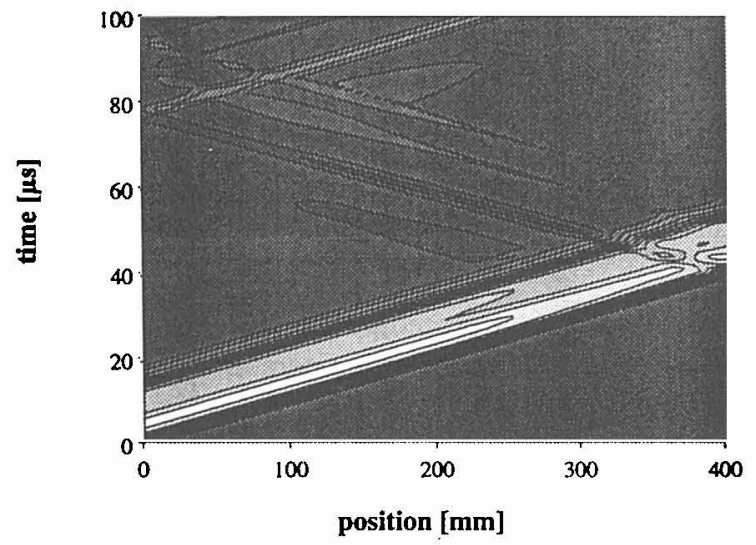

Figure 10: Superposition of the transmitted, the reflected and the secondary reflected part of the pulse at $1500^{\circ} \mathrm{C}$

\section{EXPERIMENTAL RESULTS}

Commercial alumina bars of diameter $8 \mathrm{~mm}$ and length $200 \mathrm{~mm}$ have been tested in the whole range between the room temperature and $1500^{\circ} \mathrm{C}$. The tests at the room temperature were conducted within the cold furnace, in order to check the compatibility of the results with those at the room temperature in the former experimental arrangement [4]. Two test series have been conducted, the first with altogether 28 specimens, and the second with 35 specimens tested at temperatures between $700^{\circ} \mathrm{C}$ and $1500^{\circ} \mathrm{C}$.

The results of the first series were reported [5] [6], and treated as preliminary ones, fully proving the applicability of the experimental method to the testing at elevated temperatures and its compatibility with the results at room temperature. The results of the second series presented here, Table 1, concern the accuracy of the spalling strength determination also. Each temperature point has been tested in 4 to 8 shots in order to enable the determination of the experimental scatter of the method. The scatter varies between $3 \%$ and $11 \%$ of the mean value of the strength. Compared to the room temperature tests [4] no increase of the scatter has been observed at elevated temperature experiments.

Table 1: Experimental results

\begin{tabular}{|l|c|c|c|c|c|}
\hline temperature $\left[{ }^{\circ} \mathrm{C}\right]$ & 700 & 1000 & 1200 & 1400 & 1500 \\
\hline no. of specimens & 5 & 4 & 8 & 4 & 4 \\
\hline mean strength [MPa] & 268 & 236 & 223 & 250 & 225 \\
\hline scatter [MPa] & 16 & 12 & 24 & 7 & 25 \\
\hline scatter [\%] & 6 & 5 & 11 & 3 & 11 \\
\hline
\end{tabular}

One observes a continuous decay of the mean spalling strength with the increase of the temperature up to $1500^{\circ} \mathrm{C}$. The decay is substantially stronger than anticipated in the preliminary series [4], where no pulse-matching procedure had been applied in the evaluation. The results also extend the earlier 
observations [5] [6], and enable to introduce a linear spalling strength dependence on the temperature Figure 11.

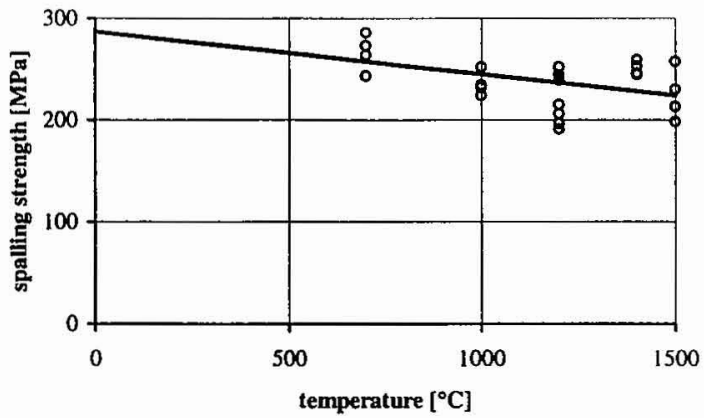

Figure 11: Experimental results for specimens with full cross-section, $8 \mathrm{~mm}$ diameter

\section{CONCLUSION}

The new experimental set-up and evaluation procedure enable very efficient determination of strength parameters in spalling of ceramics at a wide range of temperatures, combining low costs with relatively high accuracy of the results.

\section{ACKNOWLEDGEMENTS}

The work presented here has been performed in relation with the DFG project Na218/1-2 on dynamic testing of high performance ceramics. The financial support of the German Research Foundation (DFG) is hereby gratefully acknowledged. Mr. C. Schrott's co-operation has been of great help in conducting the experiments.

\section{REFERENCES}

[1] Najar, J., Dynamic tensile fracture phenomena at wave propagation in ceramic bars, Mechanical and Physical Behaviour of Materials under Dynamic Loading, Proc. Int. Symp. EURODYMAT 94, Oxford, J. Harding ed., Les Editions de Physique, J. de Physique IV, v. 4, Sept. 1994, 647-652

[2] Mikrobruchvorgänge in $\mathrm{Al}_{2} \mathrm{O}_{3}$-Keramik, DFG-Abschlußkolloquium, Jülich, 1990, H. Nickel, R. W. Steinbrech (Hrsgb.), Reihe: Konferenzen des Forschungszentrum Jülich, B. 7, 1991

[3] Müller-Bechtel, M.; Najar, J., Spalling of alumina ceramics in uniaxial stress at elevated temperatures, Material and structural modelling in collision research, Proc. $9^{\text {th }}$ DYMAT Tech. Conf., TUM, 1995, J. Najar ed., Munich, 1995 , ch. 2

[4] Bierwirth, S., Verfahren zur Bestimmung dynamischer Zugbruchparameter von Hochleistungskeramik, FortschrittBerichte VDI, Reihe 18: Mechanik/Bruchmechanik, Nr. 148, VDI-Verlag, Düsseldorf, 1994

[5] Müller-Bechtel, M.; Najar, J., Spalling fracture experiments with alumina bars at elevated temperatures, Local strain and temperature measurements in non-uniform fields at elevated temperatures, Proc. Symp. Berlin, Germany, 14 - 15 March 1996, J. Ziebs et al. ed., Woodhead publishing Ltd., Cambridge, 1996

[6] Najar J.; Müller-Bechtel, M., Spalling fracture experiments with ceramic bars at elevated temperatures, $31^{\text {st }}$ Polish Solid Mech. Conf., Mierki, Poland, Sept 9 - 14, 1996, Archives of Mechanics 2/97, Warsaw 1997 